\title{
Examining the reliability and validity of the Turkish version of the Trait Meta-Mood Scale
}

\author{
Asl1 Bugay ${ }^{1}$ \\ İdil Aksöz ${ }^{2}$ \\ Özgür Erdur Baker ${ }^{3}$
}

\begin{abstract}
The aim of the study was to investigate the reliability and validity of the Trait Meta-Mood Scale in a Turkish sample. Trait Meta-Mood Scale (TMMS), The Satisfaction with Life Scale (SWLS), Ruminative Response Scale (RRS), and Beck Depression Inventory (BDI) were administered to 387 (271 females and 113 males) university students with a mean age of 21.77 (SD = 1.65). In the present study, the Turkish model and the original model of TMMS were tested to examine which of the two model yields the better goodness of fit to the Turkish sample. Moreover, internal consistency coefficients were performed to examine the reliability of the original model. The results suggested that the original three-factor model fits the current sample better with valid and reliable scores for Turkish university students. The scale also showed acceptable interitem reliability and adequate criterion-related validity. Particularly, Clarity of Feelings and Mood Repair subscales were positively correlated with life satisfaction but Attention to Feelings was not. Additionally, rumination was negatively correlated to Clarity of Feelings and Mood Repair, but it was not significantly correlated to Attention to Feelings. Finally, depression was negatively correlated to all subscales of TMMS.
\end{abstract}

Keywords: Attention to feelings; Clarity of feelings; Mood repair, Scale adaptation; Trait metamood scale

\section{Introduction}

Meta-mood is a process of an individual's reflecting, monitoring, evaluating and regulating his/her feelings (Mayer \& Gaschke, 1988). This process involves thinking about mood, examining the relationship between mood and thoughts, maintaining good moods, and altering bad moods. Basically, the entire meta-mood process consists of being aware of one's current mood, defining the

\footnotetext{
${ }^{1}$ Ph.D, TED University, Faculty of Education, Department of Educational Sciences, asli.bugay@,tedu.edu.tr

2 Ph.D. candidate, Middle East Technical University, Department of Educational Sciences, Faculty of Education, iaksoz@metu.edu.tr

3 Ph.D., Middle East Technical University, Department of Educational Sciences, Faculty of Education, erdur@metu.edu.tr
} 
Bugay, A., Aksöz, I., \& Erdur Baker, O. (2014). Examining the reliability and validity of the Turkish version of the Trait Meta-Mood Scale. International Journal of Human Sciences, 11(2), 1264-1273. doi: 10.14687/ijhs.v11i2.3007

differences amongst all moods, and if needed, changing the current mood to a better one (Mayer, 1986). As soon as an individual starts thinking about his/her own moods, the meta-mood process starts. Trait meta-mood is considered as one of the two dimensions of emotional intelligence (Thompson, Waltz, Croyle, \& Pepper, 2007). Individuals with high emotional intelligence pay more attention to their feelings than the individuals with low emotional intelligence (Salovey \& Mayer, 1990). Accordingly, meta-mood literature reflects individuals' emotional experiences and their subjective perceptions of their emotions. Mayer, Salovey, Gomberg-Kaufman, and Blainey (1991) discuss that "the experience of mood is broader than its emotional content alone" (p.100). According to these authors, in meta-mood experiences, emotion-related (including physical, emotional, and cognitive aspects of emotions) and emotion-management-related (thoughts of action, suppression, and denial aspects of emotion management) mood experiences take place simultaneously. Salovey, Mayer, Goldman, Turvey, and Palfai (1995) emphasize that individuals differ in terms of their meta-mood skills and their way of processing meta-mood experiences because coping with a stressful experience relies on a capacity to "discriminate, attend, and regulate" feelings. Individuals regulate and attend to their emotions based on their thoughts/beliefs about emotions.

Three sub-dimensions of meta-mood are proposed by Salovey et al. (1995). These dimensions are (a) Attention to Feelings which is the ability to define feelings (b) Clarity of Feelings which is the ability to distinguish among emotions and (c) Mood Repair which is the ability to change emotions if there is a need. Meta-mood with its three dimensions is related to many different variables varying from empathy, depression, life satisfaction, rumination to emotionoriented coping (Extremera, Durán, \& Rey, 2009; Extremera \& Fernandez-Berrocal, 2005; Fernández-Berrocal, Extremera, \& Ramos, 2004; Fitness \& Curtis, 2005; Thompson, et al., 2007). However, after a close inspection of the related studies, it was found that the three dimensions relate with the variables in different ways, as suggested by Salovey et al. (1995) in their scale construction study. Other studies also supported that three subscales are working in different ways, showing that the three subscales measure different aspects of emotional intelligence. For example, depression (Fernández-Berrocal et al., 2004) and emotion-oriented coping (Fitness \& Curtis, 2005) were positively associated with attention to feelings but negatively associated with both clarity of feelings and mood repair. Yet, life satisfaction was positively associated to clarity of feelings and mood repair (Extremera et al., 2009; Fernández-Berrocal et al., 2004), and it was not related to attention to feelings (Thompson et al., 2007). In their study, Fernández-Berrocal et al. (2004) also found that rumination was positively related to attention to feelings, and negatively related to mood repair, while it was not significantly related to clarity of feelings. Finally, empathy was positively 
Bugay, A., Aksöz, I., \& Erdur Baker, O. (2014). Examining the reliability and validity of the Turkish version of the Trait Meta-Mood Scale. International Journal of Human Sciences, 11(2), 1264-1273. doi: 10.14687/ijhs.v11i2.3007

associated with attention to feelings while there was not a significant relationship with both clarity of feelings and mood repair (Fitness \& Curtis, 2005). Therefore, attention to feelings appears to have somewhat different relationships to other variables then clarity of feelings and mood repair.

Since meta-mood has been widely studied and found to be interrelated to many different trait and outcome variables, its operationalization appears to be crucial for researchers. With the aim of measuring meta-mood, Mayer and Gaschke (1988) developed the Meta-Mood Experience Scale that emphasizes moment-by-moment changes only. However, Salovey et al. (1995) considered the structure of moods as both having stable and unstable aspects. Therefore, they revised the Meta-Mood Experience Scale and renamed it as the State Meta-Mood Scale (SMMS), which considered addressing only the thoughts about the ongoing mood experience (Mayer \& Stevens, 1994). With a further study, Salovey et al. (1995) developed the Trait Meta-Mood Scale (TMMS) to measure and monitor stable experiences of moods and emotions.

The TMMS was designed to monitor individual differences in terms of attention to moods and emotions, clearly distinguishing and regulating them. In the first version, TMMS consisted of 48 items, categorized under three subscales: Attention to Feelings, Clarity of Feelings, and Repair of Mood (Salovey et al., 1995). This version of the scale included some items with lower loadings, and overlapping variances between Clarity of Feelings and Repair of Mood subscales. Thus the authors revised the scale resulting in a shorter version with 30 items with higher loadings $(\geq .40)$ and internal consistency values as high as the longer version. With these findings, Salovey et al. (1995) indicated that the shorter version was more effective. The three subscales of TMMS also showed evidence for the criterion validity.

TMMS was widely used and adapted to different languages as well. However, its factorial structure appears to be somewhat questionable as most researchers reported some modification to obtain better fits for their samples. The three factor structures of TMMS with 30-items was adapted to German (Otto, Döring-Seipel, Grebe, \& Lantermann, 2001), Spanish (Fernández-Berrocal et al., 2004), French (Rodrigue \& Clamageran, n.d.), Portugese (Queirós, Fernández-Berrocal, Extremera, Carral, \& Queirós, 2005), Farsi (Bayani, 2009), and Australian (Palmer, Gignac, Bates, \& Stough, 2003). All of these studies reported good reliability and validity values for their sample but some reached such conclusion only after some modification on the item structure. A Turkish pilot study by Aksöz, Bugay, and Erdur-Baker (2010) also reported that the scale produced valid and reliable scores for Turkish university students yet suggested further research on the factorial structure of the scale. Thus, this study aims to provide more data about the factor structure of the scale and examine whether it produces reliable and valid scores of the Turkish population. 
Bugay, A., Aksöz, I., \& Erdur Baker, O. (2014). Examining the reliability and validity of the Turkish version of the Trait Meta-Mood Scale. International Journal of Human Sciences, 11(2), 1264-1273. doi: 10.14687/ijhs.v11i2.3007

\section{Method}

\section{Participants and Procedure}

The participants consisted of 387 (271 females and 113 males) university students. 56 participants (14.5\%) were freshmen, $105(27.1 \%)$ were sophomores, $41(10.6 \%)$ were juniors, 150 $(38.8 \%)$ were seniors and $31(8 \%)$ were graduate students. Their mean age was 21.77 years $(S D=$ 1.65). After obtaining the necessary permission and consent for data collection, two of the researchers visited the departments that had agreed to participate in the study. Participants were guaranteed anonymity of their responses and confidentiality of the data. A packet of self-report measures was administered in a class hour. The completion of the survey took approximately 15-20 minutes.

\section{Measures}

Trait Meta-Mood Scale (TMMS). TMMS was developed by Salovey et al. (1995) to examine the ability of individuals to understand their mood to monitor the degree to which individuals moderate their moods, and to discover the relationship among the feelings and thoughts. TMMS is a 30-item 5-point Likert-type scale with three subscales: "attention to feelings", "clarity of feelings", and "repair of mood". Attention to Feelings is the ability of the individuals to define their feelings (e.g., I don't think it's worth paying attention to your emotions or moods); Clarity of Feelings is the ability to name the differences among emotions (e.g., Sometimes I can't tell what my feelings are); and Mood Repair is the capacity to change the emotions to better ones when needed (e.g., No matter how badly I feel, I try to think about pleasant things). Attention to feelings consists of items $1,4,15,17,18,20,21,24,26,27,28,29$, and 30 . Clarity of feelings consists of items $3,6,7,8,10$, $12,13,19,22,23$, and 25 . Repair of mood consists of items 2, 5, 9, 11, 14, and 16. The intercorrelations among subscales ranged from .82 to .87 (Salovey et al., 1995).

The Satisfaction with Life Scale (SWLS). SWLS was developed by Diener, Emmons, Larsen, and Griffin (1985) to assess global life satisfaction. The SWLS is a 5-item and 7-point Likert-type scale. Higher scores reveal a higher level of life satisfaction. The two-month test-retest correlation coefficient was .82, and the alpha coefficient was .87 (Diener et al., 1985). The Turkish version of the scale adapted by Köker (1991) was reported to have an internal consistency coefficient of .80, and a test-retest reliability coefficient of .85 . The internal reliability coefficient was .84 for the present study.

Ruminative Response Scale (RRS). RSS was developed by Nolen-Hoeksema and Morrow 
Bugay, A., Aksöz, I., \& Erdur Baker, O. (2014). Examining the reliability and validity of the Turkish version of the Trait Meta-Mood Scale. International Journal of Human Sciences, 11(2), 1264-1273. doi: 10.14687/ijhs.v11i2.3007

(1991) to measure the tendency for rumination. A sample item reads as "within the past 2 weeks how often did you think about how hard it is to concentrate." Each item is scored on a 4-point rating scale ranging from $1=$ Almost Never to $4=$ Almost Always. Higher scores on RRS indicate a higher tendency for rumination. The RRS has high internal reliability with Cronbach's alphas ranging from .88 to .90 (Luminet, 2004). A strong test-retest reliability $(r=.80)$ of six months interval was reported by Nolen-Hoeksema, Parker, and Larson (1994). The psychometric properties of the Turkish version of RRS were examined by Erdur-Baker and Bugay (2012). Their findings revealed that the scale is valid and reliable for Turkish samples. The internal reliability coefficient was .86 for the current sample.

Beck Depression Inventory (BDI). BDI is a widely used and well known self-report inventory designed to reflect the intensity of depression in clinical and normal patients. Each item is scored on a scale ranging from $0=$ Minimal to $3=$ Severe. Possible scores range from 0 to 63 . As for the psychometric properties of the Turkish version of the BDI, Hisli (1989) reported that the test-retest reliability value was .65. The Turkish version of BDI was found to be highly correlated with the depression subscale of Minnesota Multiphasic Personality Inventory. The inter item correlation coefficients were found as .92 for the current data.

\section{Results}

Means, standard deviations and internal consistency reliabilities (coefficient alpha) for all measured variables are presented in Table 1.

Table 1

Means, Standard Deviations and Reliabilities for Subscales and Measures

\begin{tabular}{lccc}
\hline Variables & $M$ & $S D$ & $a$ \\
\hline Attention to Feelings & 3.44 & .55 & .76 \\
Clarity of Feelings & 3.31 & .53 & .73 \\
Mood Repair & 3.28 & .64 & .60 \\
SWLS & 4.39 & 1.22 & .84 \\
RRS & 2.12 & .43 & .86 \\
BDI & 13.01 & 10.23 & .92 \\
\hline
\end{tabular}

\section{Confirmatory Factor Analysis (CFA)}

AMOS version 16.0 software (Arbuckle, 2007) was used to perform CFA with item parceling technique. The technique of parceling items can be used to decrease the number of indicators of lengthy scales, to obtain more continuous and normally distributed data and to improve the fit of the CFA model (Bandalos \& Finney, 2001). In the present study, the Turkish 
Bugay, A., Aksöz, I., \& Erdur Baker, O. (2014). Examining the reliability and validity of the Turkish version of the Trait Meta-Mood Scale. International Journal of Human Sciences, 11(2), 1264-1273. doi: 10.14687/ijhs.v11i2.3007

model suggested by Aksöz et al. (2010) and the original model proposed by Salovey et al. (1995) were tested to examine which of the two forms yields the better goodness of fit to the data. First, a CFA was conducted on the 27 items of the Turkish model of TMSS suggested by Aksöz et al. (2010). Based on the item parceling technique used in the current study, Factor 1 (Attention to Feelings) consists of 3 item parcels, Factor 2 (Clarity of Feelings) consists of 2 item parcels, and Factor 3 (Mood Repair) consists of 3 item parcels. The result indicated poor model fit indices for the Turkish model $\left[\chi^{2}(17)=58.953, p=.00 ; \chi^{2} / d f\right.$-ratio $=3.468 ; G F I=.897, C F I=.881, R M S E A$ $=.080$, and $S R M R=.053]$. Also, the model had adequate inter-item reliability for Attention to Feelings $(a=.81)$, and for Clarity of Feelings $(a=.76)$. However, the inter-item reliability for Mood Repair $(a=.38)$ was found to be considerably lower than other two sub factors.

Subsequently, another CFA was conducted on the 30 items of the original three factor model of TMMS proposed by Salovey et al. (1995). According to the item parceling technique, Factor 1 (Attention to Feelings) consists of 4 item parcels, Factor 2 (Clarity of Feelings) consists of 3 item parcels, and Factor 3 (Mood Repair) consists of 2 item parcels. Each item parcel includes 3 or 4 items which were selected based on their skewness and kurtosis values. The skewness and kurtosis values of the item parcels ranged from .056 to -.518 indicating the normal distribution of the item parcels.

The result indicated good model fit indices for the original three-factor structure $\left[\chi^{2}(24)=\right.$ 57.751, $p=.00 ; \chi^{2} / d f$ ratio $=2.406 ; G F I=.969, C F I=.963, R M S E A=.060$, and SRMR $\left.=.038\right]$. Parameter estimation is presented in Table 2. Each parameter's estimated value (column1), standard error (column 2), and critical ratio (column 3) are listed.

Table 2

Parameter Estimates of TMMS

\begin{tabular}{llccccc}
\hline & & & weight & S.E. & C.R. & $p$ \\
\hline parcel 1 & $<---$ & Attention to Feelings & .707 & & & \\
parcel 2 & $<---$ & Attention to Feelings & .669 & .080 & 11.217 & $<.001$ \\
parcel 3 & $<---$ & Attention to Feelings & .575 & .085 & 9.819 & $<.001$ \\
parcel 4 & $<---$ & Attention to Feelings & .820 & .119 & 12.450 & $<.001$ \\
parcel 5 & $<---$ & Clarity of Feelings & .469 & & & \\
parcel 6 & $<---$ & Clarity of Feelings & .793 & .253 & 7.787 & $<.001$ \\
parcel 7 & $<---$ & Clarity of Feelings & .693 & .181 & 7.686 & $<.001$ \\
parcel 8 & $<---$ & Mood Repair & .840 & & & \\
parcel 9 & $<---$ & Mood Repair & .820 & .171 & 7.593 & $<.001$ \\
\hline
\end{tabular}


The result of estimated correlation coefficients of each factor revealed that The Meta-Mood sub-factors were significantly correlated (Attention to Feelings and Clarity of Feelings, $r=.38$, Clarity of Feelings and Mood Repair, $r=.63$, Attention to Feelings and Mood Repair, $r=.23$ ). Therefore, the original three-factor structure with 30 items was confirmed with the current data. Further validity and reliability analyses were conducted only for the original three-factor structure of the scale.

Internal Consistency Reliability. Internal consistency coefficient (Cronbach's alpha) was calculated for the subscales of TMMS respectively. Cronbach's alpha was $a=.76$ for Attention to Feelings subscale, was $a=.73$ for Clarity of Feelings subscale, and was $a=.60$ for Repair of Mood subscale.

Criterion-Related Validity. Pearson correlation coefficients among TMMS, SWLS, and RRS scores were calculated to test the criterion-related validity of the scale (see Table 3). SWLS significantly correlated with Clarity of Feelings $(r=.39, p<.001)$ and Mood Repair $(r=.41, p<$ $.001)$, but did not correlate with Attention to Feelings $(r=.09, p=.06)$.

Table 3

Correlations among the TMMS, SWLS, RRS, and BDI

\begin{tabular}{lcccccc}
\hline Variables & 1 & 2 & 3 & 4 & 5 & 6 \\
\hline Attention to Feelings & 1 & $.28^{* *}$ & $.19^{* *}$ & .09 & -.006 & $-.11^{*}$ \\
Clarity of Feelings & & 1 & $.43^{* *}$ & $.39^{* *}$ & $-.42^{* *}$ & $-.44^{* *}$ \\
Mood Repair & & & 1 & $.41^{* *}$ & $-.40^{* *}$ & $-.43^{* *}$ \\
SWLS & & & & 1 & $-.48^{* *}$ & $-.55^{* *}$ \\
RRS & & & & 1 & $.59^{* *}$ \\
BDI & & & & & 1 \\
\hline${ }^{*}<<.05,{ }^{* *} p<.001$ & & & & &
\end{tabular}

In addition, rumination was negatively correlated to Clarity of Feelings $(r=-.42, p<.001)$ and Mood Repair $(r=-.40, p<.001)$, but was not significantly correlated to Attention to Feelings $(r$ $=-.006, p=.90)$. Finally, BDI was negatively correlated to all subscales of TMMS: Attention to Feelings and depression $(r=-.11, p<.05)$, Clarity of Feelings and depression $(r=-.44, p<.001)$, and Mood Repair and depression $(r=-.43, p<.001)$.

\section{Discussion}

The aim of the current study was to examine reliability and validity of the Turkish version of the Trait Meta-Mood Scale. In order to test the factor structure of the TMMS, two proposed models were evaluated. The results suggested that the original three factor model fits the current 
Bugay, A., Aksöz, I., \& Erdur Baker, O. (2014). Examining the reliability and validity of the Turkish version of the Trait Meta-Mood Scale. International Journal of Human Sciences, 11(2), 1264-1273. doi: 10.14687/ijhs.v11i2.3007

sample better. The results of estimated correlation coefficients of each factor revealed that the Trait Meta Mood sub-factors were significantly correlated. These results support the theoretical view that the Trait Meta Mood (as measured by the TMMS) consists of three separate, yet related constructs. In addition, internal consistency coefficients were calculated to examine the reliability of the original three-factor model of TMMS. In the current study, the reliability of test scores for all subscales revealed good internal consistency reliability which is consistent with that reported by previous studies (e.g., Fernandez-Berrocal et al., 2004; Salovey et al., 1995).

Furthermore, the criterion-related validity of the scale was established by using correlation analysis. Although the original factor structure of TMMS was significantly related to life satisfaction, rumination, and depression, the directions and the nature of correlations were found to be different as the previous studies have already reported (Gross \& John, 2003; Fernández-Berrocal et al., 2004). Particularly, Clarity of Feelings and Mood Repair were positively correlated with life satisfaction as reported by previous studies (Extremera et al., 2009; Fernández-Berrocal et al., 2004). However, Attention to Feelings was not related to life satisfaction, which supports the results of Thompson et al. (2007). In addition, rumination was negatively correlated to Clarity of Feelings and Mood Repair, but it was not significantly correlated to Attention to Feelings. Finally, in the current study, depression was negatively correlated to all subscales of TMMS. According to the results, particularly Clarity of Feelings and Mood Repair seem to have a preventive role in predicting risk for emotional disorders. Such results should be useful for intervention and prevention efforts to assess and monitor students with emotional regulation difficulties. Therefore, the scale can be used as an assessment tool by practitioners working with clients' emotional problems to better understand and raise awareness of the clients' emotion regulation and its effect on their well-being.

In the future, in depth cultural and/or cross-cultural studies will be helpful to further examine any cultural variations on meta-mood experiences and how to manifest these experiences. The study suggests that TMMS may be used for international samples. This study is not without limitations, including the non-representativeness of the sample. Furthermore, the present results are based on a cross-sectional design that prevents any longitudinal predictions. Therefore, future studies should cross-validate the results of this study with different validity and reliability tests by utilizing different samples. For example, future researchers may want to address test-retest reliability by using different community samples to determine the instrument's reliability over time. 
Bugay, A., Aksöz, I., \& Erdur Baker, O. (2014). Examining the reliability and validity of the Turkish version of the Trait Meta-Mood Scale. International Journal of Human Sciences, 11(2), 1264-1273. doi: 10.14687/ijhs.v11i2.3007

\section{References}

Aksöz, I., Bugay, A., \& Erdur-Baker, Ö. (2010). Turkish adaptation of the Trait Meta-Mood Scale. Procedia Social and Behavioral Sciences, 2, 2642-2646. doi:10.1016/j.sbspro.2010.03.387

Arbuckle, J. L. (2007). Amos 16.0 User's Guide. Chicago: SPSS.

Bandalos, D. L., \& Finney, S. J. (2001). Item parceling issues in structural equation modeling. In G. A. Marcoulides \& R. E. Schumacker (Eds.), Advanced structural equation modeling: New developments and techniques (pp. 269-296). Mahwah, NJ: Lawrence Erlbaum Associates, Inc.

Bayani, A. A. (2009). Psychometric data for a Farsi translation of the Trait Meta-Mood Scale. Psychological Reports, 105(1), 198-204. doi:10.2466/pr0.105.1.198-204

Diener, E., Emmons, R. A., Larsen, R. J., \& Griffin, S. (1985). The Satisfaction with Life Scale. Journal of Personality Assessment, 49, 71-75.

Erdur-Baker, O. \& Bugay, A. (2012). The Turkish version of the Ruminative Response Scale: An examination of its reliability and validity. The International Journal of Educational and Psychological Assessment, 10(2), 1-16

Extremera, N., Durán, A., \& Rey, L. (2009). The moderating effect of trait meta-mood and perceived stress on life satisfaction. Personality and Individual Differences, 47, 116-121. doi:10.1016/j.paid.2009.02.007

Extremera, N., \& Fernandez-Berrocal, P. (2005). Perceived emotional intelligence and life satisfaction: Predictive and incremental validity using the Trait Meta-Mood Scale. Personality and Individual Differences, 39, 937-948. doi:10.1016/j.paid.2005.03.012

Fernández-Berrocal, P., Extremera, N., \& Ramos, N. (2004). Validity and reliability of the Spanish modified version of the Trait Meta-Mood Scale. Psychological Reports, 94, 751-755.

Fitness, J., \& Curtis, M. (2005). Emotional intelligence and the Trait Meta-Mood Scale: Relationships with empathy, attributional complexity, self-control, and responses to interpersonal conflict. E-Journal of Applied Psychology: Social Section, 1(1), 50-62. Retrieved August 26, 2009, from http://ojs.lib.swin.edu.au/index.php/ejap/article/viewFile/6/15

Gross, J. J., \& John, O. P. (2003). Individual differences in two emotion regulation processes: Implications for affect, relationships, and well-being. Journal of Personality and Social Psychology, 85, 348-362. doi:10.1037/0022-3514.85.2.348

Hisli, N. (1989). Reliability and validity of the Beck Depression Inventory for university students. Turkish Journal of Psychology, 7(23), 3-13.

Köker, S. (1991). Normal ve sorunlu ergenlerin yașam doyumu düzeylerinin karşılaștırlması [A comparison of life satisfaction of normal and delinquent adolescence]. (Unpublished master's thesis), Ankara University, Turkey.

Luminet, O. (2004). Assessment and measurement of rumination. In C. Papageorgiou \& A. Wells (Eds.), Rumination: Nature, theory, and treatment of negative thinking in depression. (pp. 187-215). Chichester: Wiley.

Mayer, J. D. (1986). How mood influences cognition. In N. E. Sharkey (Ed.), Advances in Cognitive Science (pp. 290-314). Chichester, West Sussex: Ellis Harwood Limited.

Mayer, J. D. \& Gaschke, Y. N. (1988). The experience and meta-experience of mood. Journal of Personality and Social Psychology, 55(1), 102-111.

Mayer, J. D., Salovey, P., Gomberg-Kaufman, S., \& Blainey, K. (1991). A broader conception of mood experience. Journal of Personality and Social Psychology, 60, 100-111. doi:10.1037/00223514.60.1.100

Mayer, J. D., \& Stevens, A. A. (1994). An emerging understanding of the reflective (meta-) experience of mood. Journal of Research in Personality, 28, 351-373.

Nolen-Hoeksema, S., \& Morrow, J. (1991). A prospective study of depression and post-traumatic stress symptoms following a natural disaster: The 1989 Loma Prieta Earthquake. Journal of Personality and Social Psychology, 61(1), 115-121. doi:10.1037/0022-3514.61.1.115 
Nolen-Hoeksema, S., Parker, L. E., \& Larson, J. (1994). Ruminative coping with depressed mood following loss. Journal of Personality and Social Psychology, 67(1), 92-104. doi:10.1037/00223514.67.1.92

Otto, J. H., Döring-Seipel, E., Grebe, M., \& Lantermann, E. D. (2001). Development of a questionnaire for measuring perceived emotional intelligence: Attention to, clarity, and repair of emotions. Diagnostica, 47, 178-187. doi:10.1026//0012-1924.47.4.178

Queirós, M. M., Fernández-Berrocal, P., Extremera, N., Carral, J. M., \& Queirós, P. S. (2005). Validação e fiabilidade da versão portuguesa modificada da Trait Meta-Mood Scale. Revista de Psicologia, Educação e Cultura, 9(1), 199-216.

Palmer, B. R., Gignac, G., Bates, T., \& Stough, C. (2003). Examining the structure of the Trait Meta-Mood Scale. Australian Journal of Psychology, 55, 154-159. doi:10.1080/0004953042000298612

Rodrigue, S., \& Clamageran, S. (n.d.). Retrieved November 13, 2009, from http://www.unh.edu/emotional intelligence/ei $\% 20$ Measuring $\% 20 \mathrm{Mood} / \mathrm{mm} \% 20 \mathrm{TTSM}$ \%20French\%20TMMS.htm

Salovey, P., \& Mayer, J. D. (1990). Emotional intelligence. Imagination, Cognition and Personality, 9, 185-211.

Salovey, P., Mayer, J. D., Goldman, S. L., Turvey, C., \& Palfai, T. P. (1995). Emotional attention, clarity, and repair: Exploring emotional intelligence using the Trait Meta-Mood Scale. In J. W. Pennebaker (Ed.), Emotion, disclosure, and health (pp. 125-154). Washington, D.C.: American Psychological Association.

Thompson, B. L., Waltz, J., Croyle, K., \& Pepper, A. C. (2007). Trait meta-mood and affect as predictors of somatic symptoms and life satisfaction. Personality and Individual Differences, 43, 1786-1795. doi:10.1016/j.paid.2007.05.017 